\title{
Supportive Drivers of Organizational Knowledge Management: A Case Study from Egypt
}

\author{
Randa El Bedawy ${ }^{1}$ \\ ${ }^{1}$ Misr International University, Egypt \\ Correspondence: Randa El Bedawy, Faculty of Business Administration and International Trade, Misr \\ International University, Egypt. E-mail: randa.bedawy@miuegypt.edu.eg
}

Received: March 21, 2018

doi:10.5539/ijbm.v13n6p183
Accepted: May 6, 2018

Online Published: May 15, 2018

URL: https://doi.org/10.5539/ijbm.v13n6p183

\begin{abstract}
The ability to manage efficiently the flow of knowledge has becoming a crucial requirement to boost the organizational learning and competitiveness along the knowledge era. However, a lack of consensus and confusion may still exist regarding what comprise the Knowledge Management (KM) and its importance to improve the overall organizational performance in Egypt. Moreover, there is generally a lack of an observable organizational KM initiatives' progress in Egypt. This study highlights the significance of KM and explores the key drivers that can support organizational KM initiative in Egypt which requires organizational management and human orientation in terms of setting supportive human resource management, organizational culture and organizational structure. The study also alarms the attention to the various challenges that may hinder the successful implementation of KM initiative in Egypt. Based on the case study approach, this study sheds the light on a good model of IBM Egypt as a guidance supporting the crucial significance of KM for booming innovation and organizational performance.
\end{abstract}

Keywords: knowledge, knowledge management, innovation, human resource management, organizational culture, organizational structure

\section{Introduction}

In the Knowledge era, the ability to create, diffuse and manage efficiently the flow of knowledge has becoming extremely important requirement to create organization learning and competitiveness. However, there is still lack of consensus and even confusion that still may exist regarding what can constitute Knowledge Management (KM) concept (Wahba 2015; Tomas, 2003). KM has gained recently a growing attention to enhance and support the knowledge creation and sharing within organizations for achieving better organizational performance (Wu 2013; Chowdhury 2016). There are various types of knowledge but a basic difference is between the tacit and the explicit knowledge. Tacit knowledge resides in people's minds and it is generally difficult to articulate. On the other hand, the explicit knowledge can exist in various forms as documents or arranged data or any other explicit forms. A main problem of KM is to explain the tacit knowledge and make it available for others to use it. KM is not only about the dissemination of knowledge, but it is more important to ensure that the right knowledge to be provided to the right people at the right time as well as to be shared to develop organizational learning and successful performance. Current perspectives emphasize the importance of KM to support organizations for solving their problems as well as for maintaining their competitive advantage (Makhmutov 2016; Bohle 2016; Mir 2015).The objective of this study is to explore the required supportive drivers for developing and sustaining successfully the KM initiative. The study sheds also the light on the importance of KM as well as the challenges that may hinder its successful implementation. The case study elaborates the KM approach in IBM Egypt as an illustration of excellence to share best practices and to provide a good base for guiding other organizations to embed KM initiative for better performance.

\section{Literature Review}

\subsection{Knowledge Management}

\subsubsection{Knowledge Management: Perspectives and Significance}

Knowledge is considered currently a main factor impacting the organization's competitiveness because of the fierce global competition, which requires in turn knowledge to be effectively managed. However, KM faces 
various challenges as knowledge itself is a multifaceted conception. The word "knowledge" is one of the most ambiguous words in English language as it is a multi faceted concept having many interpretations. In order to analyze the definition of knowledge, it is necessary to consider various attributes such as its quality in terms of the reliability, accuracy, or completeness. Another attribute can be its demand in terms of the value, usefulness, relevance or cost. Descriptive characteristics is also another attribute in terms of the carrier source either human material, media, audio, graphic or numeric, as well attributes such as its volume in terms of the amount of information and its specialization in terms the field of its concerns. Makhmutov (2016) points out that knowledge is much more complex and broader concept than information or data as it is more valuable and useful. Knowledge may encompass methodologies, concepts, values, skills or judgments, and know how. Knowledge is a mix of experience, information and intuition which can develop a base for accumulating more new information. Knowledge can be set not only in documents but as well in organizations' policies, practices, norms, or competencies to support making effective decisions as well as it is a main base for organizations to acquire competitive advantages through maintaining a learning culture and converting knowledge into achievements and good practices.

Accordingly, organizational knowledge has become a strategically crucial intangible asset to achieve successfully the required outcomes and it has become a main source of competitive factor for organizational improvement and expansion (Makhmutov, 2016). According to King (2009), there are three levels of knowledge. First is the 'know what level' as specifying what action to be taken when presented to various set of stimulus. Second is the 'know how level' as deciding the suitable response to a stimulus and the third is the 'know why level' as having a profound understanding of basic relationships and uncertainty levels related to a stimuli. According to Bohle (2016), Knowledge reflects the ability of the organization to operate successfully for attaining the intentional outcomes and it is also a learning procedure to internalize new valuable knowledge. For Soliman (2000), knowledge can be defined as the capacity to develop a knowledge map for using 'Knowledge Treasures' successfully to reach organization's goals. El Badawy (2015) defines Knowledge as the person's accumulation of information that fulfills the achievement of goals. Although Knowledge was perceived in the past as a base for maintaining competitive advantage, yet currently there has been remarkable changes in the means knowledge can be created, developed and communicated (Quintas, 1997). In spite of perceiving knowledge as a valuable intellectual asset, it has some contradictory features such as the knowledge's transfer doesn't lead to losing it or such as the scarce ability to use knowledge although its abundance (Dalkir, 2005). According to Mir (2015), although knowledge can have various meanings depending on various perspectives but knowledge communication in organizations should involve usually technology. Knowledge reflects the business value that can generate and maintain wealth for the organization to promote its performance and competitiveness. However, it should also be applied to various organizational levels such the individual, the group, and the organization levels (Groff, 2012).

Yet, it is challenging for any organization to manage huge amount of information and to let knowledge be available at the right time, which in turn requires urgently setting KM initiative in the organization. Knowledge is considered the major wealth of an organization that should be attained; taking into consideration that knowledge is a never ending reference that can be still subjected to growth and development in the global competitive business world. Then organizations should set KM initiative to maintain its success (Wahba, 2015). Over the past years, knowledge has been crucial to various organizations in the new knowledge age (Mir, 2015). According to (Tomas, 2003), knowledge is a vital strategic asset that should be leveraged to attain achievements in the global competition and marketplace. Gascó (2017) confirms that it is generally believed that knowledge is one of resources which support the competitive advantage as the development of any organization is affected mainly by its knowledge's accumulation.

Accordingly, recently there is a significant attention from both the academic and business levels to study KM. In spite of KM importance, there is still no generally a single definition to study it. Knowledge has been generally recognized as a major element for successful business's operations. Accordingly it is essential to set successful ways to manage knowledge. KM becomes a basic concept in current business world, as becoming one of the pillars to develop different organizations' strategies and policies (Gascó 2017; Caiazza 2015; Kraśnicka 2016). Knowledge is a key valuable economic resource that must be well managed to sustain a learning organization. Since the early seventeenth century, the importance of knowledge was perceived as wealth and lots of researchers have confirmed the value and worth of knowledge. Knowledge then requires its management to create value for itself. It is crucial to develop an organization broad strategic policy for acquiring, developing, and applying knowledge within the organization as well as to monitor and evaluate the outcomes of knowledge assets (Quintas 1997; Caiazza 2015). 
The aim of KM is to manage information that is spread among employees at different levels and the main concern then should be how KM can be best achieved and employed inside the organization (Wang 2012; Braedley 2016). A main concern of KM is to exploit the tacit knowledge and make it available as well for others to employ it (King, 2009). Noticeably, the 1990's marked the starting growing attention to KM from both the academic and management levels (El Badawy, 2015). According to (Groff, 2012), KM can be defined as the systematic process inside the organization for capturing, structuring, managing and disseminating knowledge for efficient work. The term KM gets its roots from various disciplines and its popularly started since late 1980s as an intellectual capital as core competencies and capabilities that have progressively become more valuable than the more traditional concrete physical assets. Because knowledge is much more complex than data or information as it is more subjective and greatly contextual, each organization should set and apply its KM processes based on its business objectives. According to King (2009), the aim of KM is to leverage and to improve organization's knowledge assets through improving the knowledge process, which in turn will improve the overall organizational performance. KM concentrates on the role of managers to facilitate and support achieving KM's goals as well as to motivate employees' participation to achieve successfully KM goals. Although KM should be supported with the appropriate information technology, yet KM activities are more people oriented and less technology oriented which may differ from general people perception. However, the 'KM System' refers to the application of the computer based communication and information system in the organization to maintain and promote KM process. A main difference between KM System and Information System is that 'KM System' can be less automated as it requires human input in its process. On the other hand, 'Information System' requires humans to decide the design phase but then function automatically (King, 2009). The successful KM requires new perspectives and techniques throughout the organization, adding to prepare and develop KM expertise and professionals which is still a main challenge (Dalkir 2005; Braedley 2016). Tomas (2003) points out that knowledge broadly refers to potential valuable information to an organization. Then, KM focuses on the generation and the dissemination of valuable information within an easy accessible organizational mechanism. A main part of KM process is transforming information into knowledge that can take various forms in the process requiring mutual understanding and filtering phases. According to King (2009), KM in the organization intends to manage the human resources and the work processes to effectively employ and develop the related knowledge which can be various and may include knowledge in the form of printed documents such as patents or manuals; employees' knowledge about best work practices; adding to knowledge regarding the organization's products and processes. The KM process focuses on how organizations can deploy knowledge to achieve sustainable competitive advantage for the organization. In this respect as similar to many other physical assets, the unique valuable knowledge must be well managed as its value may erode along time.

\subsubsection{Knowledge Management: Process and Cycle}

There are various models for KM processes cycle that can illustrate the relationships of the key of KM processes which are creation, acquisition, refinement, storage, and transfer. However, in common the initiation of the KM cycle should always start with the acquisition or creation of knowledge through replacing old knowledge with new one as well as developing new knowledge which involves searching for precious knowledge that may exit from outside or inside the organization. Then it is the knowledge refinement which refers to the processes of filtering and optimizing knowledge to be stored and organized into the proper layout and in the formal memory system to maximize its reusability in the long term which would require also be either transferred or shared with others to support them for developing innovation, collaborative problem solving and collective learning (King, 2009). According to $\mathrm{Wu}$ (2013), for maintaining the knowledge' creation and dissemination, KM should maintain the exchange between explicit and tacit knowledge. Tacit knowledge refers to the knowledge workers' personal experience which cannot be clearly expressed by words, but only exists in the experience and skills of employees. On the other hand, explicit knowledge refers to the information that can be verbalized and structurally organized. To generate understandable and functional knowledge, it requires members' interaction to interlink both explicit and tacit knowledge. Moreover, carrying out and maintaining successfully the KM activities may require various practices, tools and techniques targeting the key knowledge assets (Wiig 1997; Dalkir 2005; Braedley 2016). According to Kianto (2016), KM processes generally consist of knowledge creation, sharing, acquisition, transfer and application as follows:

- Knowledge acquisition aims to collect information from various organizational sources such as from customers, strategic partners or research institutions as well as from tacit knowledge which is rooted in employees' experiences that can be shared through social interaction, building a knowledge sharing activities and proper culture through enhancing the informal communication or brainstorming assemblies. 
- Knowledge creation aims to build up new valuable ideas as well as to promote innovation for sustaining good performance in dynamic business environment.

- Knowledge codification aims to codify the tacit knowledge to explicit form in order to store and to provide updated documented knowledge which requires the availability of proper IT systems that should be supported as well with employees' competencies and motivation to share their knowledge as well as to store their knowledge in various organizations' databases or manuals.

- Knowledge retention aims to attract, maintain the best employees as well as to reduce employees' turnover in order to avoid the loss of key valuable experts' knowledge.

$\mathrm{KM}$ is considered a crucial management strategy in current's global knowledge based society to develop valuable knowledge that guide sustaining competitive advantages. According to (Sunalai, 2015), KM process framework encompasses six categories as follows:

- Knowledge sharing is a process to distribute information and ideas among people.

- Knowledge storage is a process to categorize knowledge in a mechanism to be easily retrieved.

- Knowledge utilization is a process to employ knowledge to work operations.

- Knowledge creation is a process to develop new knowledge.

- Knowledge acquisition is a process to easily access the acquired knowledge.

- Knowledge assessment is a process to assure the worth and utility of knowledge.

Gascó (2017) confirms that KM is a process intending to capture, to distribute and to effectively use knowledge. Some other authors consider that KM covers phases as generation, encoding, transferring and using of knowledge while others reflect that KM covers generation, coding, refinement and transmission of knowledge. Generally, there is no set of phases of KM as it is perceived differently by various authors. Some authors emphasize various phases within the generation phase into the external knowledge acquisition and its internal creation, while others emphasize the application phase of KM to identify, to measure, to store and to transfer knowledge. However, it is confirmed generally that KM involves common major phases as the generation, coding, coordination and transfer of knowledge (Gascó 2017; Wu 2013; King 2009; Zahra 2015).

$\mathrm{KM}$ process intends to acquire, create, refine, store, transfer, share, and utilize knowledge. Then, KM main function is to operate the KM processes, adding to develop systems to support it, as well as to motivate employees to participate in KM processes. According to the knowledge spiral theory, there are four forms of basic modes or stages to create, intertwine and transform knowledge as follows:

- Socialization refers to the process of creating tacit knowledge through experience sharing, adding to interaction and communication between people.

- Externalization refers to the process of conceptualizing knowledge through clear presentation or linguistic forms encouraging members to brainstorm and communicate their experiences for knowledge creation to develop new innovative knowledge.

- Combination refers to the process of generating systematic knowledge and setting a knowledge system to develop explicit knowledge that can be classified, organized and easily acquired through various means as documents or emails.

- Internalization refers to the process of transforming explicit knowledge to personal experience and practices to be processed through learning by doing as knowledge workers acquire depth learning of explicit knowledge (Wu, 2013).

As was clarified, knowledge transfer and creation can happen in each of the above stages. Accordingly supporting successful knowledge accumulation through Human Resource Management (HRM) has become a crucial requirement for effective KM. Human resources are the basic valuable references for knowledge creation in the organization which require to search and combine effectively their heterogeneous valuable knowledge.

Wahba (2015) points out three main KM processes as follows:

- Knowledge generation which refers to the process of acquiring knowledge from both inside or outside references. The generation of knowledge requires the ability to develop new application from current knowledge.

- Knowledge sharing which refers to the process of sharing knowledge and allowing larger cooperation to understand the entire process.

- Knowledge utilization which refers to the process of applying the shared knowledge. 
However, the three above main KM processes are useless if the organization cannot employ the knowledge efficiently to improve decision making process and to adapt more successfully to environmental unpredictable changes which in turn should have a positive impact on the overall organizational performance.

KM works on turning information into easily accessible usable forms of knowledge for the people who need it. KM requires two main activities: First is to capture and document the individual explicit and tacit knowledge, and secondly its diffusion within the organization. Accordingly KM tends to build up the intellectual capital to create distinctive core competencies (Groff, 2012). According to Soliman (2000), KM activities can be classified as knowledge processing; knowledge domains; and knowledge formality. However, many organizations may still exploit five main KM processes for creating, capturing, organizing, accessing, and using knowledge. Setting strategies for the implementation of KM should be well discussed before making any major investment. It is crucial to analyze the expected benefits for the organizations. There is a crucial role of HRM to explore the tacit knowledge, to guide the best utilization of this knowledge and to ensure the alignment of KM with the business success' directions (Soliman, 2000). To set a strategy, Wahba (2015) identifies main dimensions of KM practices: first is the ability to find and to share the existing knowledge; second is the ability to create new knowledge; third is setting a culture that promotes the KM which involves the managerial activities to acquire, create, store, share, diffuse, develop, and deploy knowledge. Many of the benefits of KM are intangible and hard to be measured. Yet, it is crucial to do a business analysis before developing a KM program. The HR department acts a main role to assess employees' knowledge and to determine the expected main benefits for the organization from such analysis. A good KM strategy requires developing strategies to advance the knowledge sharing. When an organization decides to develop a KM strategy, it must analyze its market from three main perspectives which are the market needs, the main driving forces and how can the organization best provide the required knowledge. Moreover, HR department should play a main role in setting this strategy as the organization should determine how the HR department can explore and make the best use of knowledge. According to Soliman (2000), to ensure that KM program covers all the essential requirements, a set strategy should support the organization to be:

- Knowledge alert which means to focus on what the business needs to know.

- Knowledge noticeable which means to make the vital knowledge observable.

- Knowledge definite which means to focus on to the vocabulary of knowledge as customers' desires compared to customer feedback.

- Knowledge hunter which means to hit knowledge outside the organization as from competitors, customers or suppliers to become a knowledge culture.

- Knowledge sharing which means make it visible for employees as it is a main value for the organization.

- Knowledge evaluator which means measure the outcomes of KM program's implementation.

- Knowledge demonstrator which means rewarding the sharing of knowledge.

The effective implementation of KM strategy requires actually an effective role of HRM to control the employees' knowledge, adding to create a supportive work environment for KM programs through reinforcing the knowledge sharing projects as value added activities for employees. Wang (2012) points out that organizations may employ various KM processes and practices to enhance its overall performance. However, generally, there are two strategic types of KM. First is the codification of a KM strategy which is emphasizing information systems as knowledge is recorded database in order to make it easily accessible for employees. The second is maintaining knowledge by employees as sharing and dissemination of knowledge depends basically on employee's direct interaction. Most researchers have concentrated on knowledge creation which is the outcome of tacit and explicit knowledge interaction. According to King (2009), there are two KM strategies that most organizations concentrate mainly on one of them which are 'codification' and 'personalization'. The codification, is basically can be implemented in the structure of electronic documentation systems to codify, to store and to easily permit the dissemination and reuse of knowledge. On the other hand, 'personalization' intends to develop the networks to ease the transfer of knowledge and its sharing among people. Moreover, there are also other more detailed levels of KM strategies as follows:

Codification Sub-Strategies

- Systems: to create, refine knowledge and motivate people to provide the content of knowledge.

- Process: to apply, develop and use the repetitive processes that knowledge supports them.

- Commercial: to manage the organization intellectual property as patents or trademarks. 
- Strategic: to develop the knowledge capabilities to originate the competitive strategy.

Personalization Sub-Strategies

- Cartographic: to create knowledge map or network to unite people.

- Organizational: to provide intranets to facilitate the socialization practice.

- Social: to socialize as a base for creating, exchanging knowledge and to provide the physical places that can ease the discussions (King, 2009).

In turn based to their needs, some organizations may concentrate on only one strategy or may use a mixture of these strategies.

\subsection{Knowledge Management: Key Supportive Drivers}

\subsubsection{Knowledge Management: Organization Culture as a Key Supportive Driver}

There is a remarkable literature that supports, not only the importance of $\mathrm{KM}$, but also the significance impact of organizational culture to support the success of KM processes (Gascó, 2017). Organization learning culture illustrates the set of values or beliefs that guide the required organizational behavior and norms to promote KM activities (Tomas, 2003). The success of KM initiative requires a support from a proper organizational culture (Gascó 2017; Soliman 2000). Gascó (2017) points out that many researchers confirm that the prevailing organizational culture can constitute one of the most vital promoters or barriers to KM. Generally, organizational culture can either support or prevent knowledge creation, sharing and utilization. From this perspective, it is crucial to explore the types of cultures that are most appropriate for efficient KM. In general, the cultures that best support the efficient KM provide collaborative mutual work environment which focus on teamwork and functional constructive work process as well as cultures where KM is a primary dedication. These organizational cultures promote climate of trust which in turn support the social interaction and facilitate the access to knowledge. In other words, it can support the successful dissemination and employ of knowledge. Overall (2015) points out that organizational culture is a function of leadership which in turn will affect KM which next will affect the innovation. Trust and commitment of employees have been proven to be important factors to advance organizational $\mathrm{KM}$. There is a crucial role for organizational culture to influence the success KM practices to motivate people for creating, sharing and utilizing knowledge for the organization's success. Organizational culture clearly can affect the knowledge related practices inside the organization through determining the appropriate knowledge to be shared, as well as when and with who to be shared (King 2009; Sunalai 2015).

\subsubsection{Knowledge Management: Organizational Structure as a Key Supportive Driver}

Moreover, adding to setting a proper organizational culture, Wahba (2015) also strongly confirms that organizational structure plays a major role to support the implementation of KM processes which require employees' honesty, development of human resources, team work spirit, adding to increase the knowledge levels of employees and setting an effective communication system. There is a significant relationship between organizational structures and KM. Organizational structure can positively enhance KM initiative if organizational structure reflects less centralization, less formalization, and more work integration (Wahba 2015; Sunalai 2015).The availability of advanced technologies also supports the KM initiatives as it assists sharing easily the knowledge as well as the overall implementation of KM programs. The technological infrastructure should be people intensive to manage the knowledge of human resources in the organization. Yet, KM chain can be a difficult task as it requires team work and top management support to generate, capture, access and make use of this knowledge (Soliman, 2000). The more structured the implementation of KM program, the higher probability to be successful but this requires from HR department to pay more attention to the strategies of KM programs through forming the effective KM teamwork. Moreover for supporting the implementation of a KM program, the organization should consider creating a position or a leadership role to manage the process as a chief knowledge officer or a KM manager to embed the KM discipline in the organization's culture and structure. Still the HR department should create the job description for the role of KM chief officer or manager, adding to select the right person to implement the KM strategy (Soliman 2000; Wahba 2015). Accordingly the HR department is really crucial to drive successfully the KM processes. The HR management plays a crucial role to create, disseminate, use and embed successfully the organization' knowledge.

\subsubsection{Knowledge Management: Human Resource Management (HRM) as a Key Supportive Driver}

In a knowledge based world, knowledgeable employees are considered nowadays the most important asset of any organization. The interface among organizational members becomes the basic source for acquiring valuable knowledge (Wang 2012; Wu 2013). According to Wang (2012), the organization's competitive advantage 
depends basically on the employees' knowledge, competencies and capabilities. Then, employees' knowledge sharing is the human capital advantage that can develop new knowledge adding to promote unique value, efficiency and innovation inside the organization. That's why HRM should set and employ successful formal procedures for recruiting, developing and evaluating the employees' performance in order to develop successfully the organization's precious human resource capital. Although IT can be usually perceived as a main driver for KM, some others oppose this view and believe that people is the key driver of KM not the technology as the value proposition of business depends mainly on the intangibles knowledge based assets such as the employees' creativity and innovation (Soliman, 2000). The knowledge assets require a knowledge plan to describe how, what and where to find the valuable knowledge within the organization which usually can be found along employees or customers' capital. The greatest asset is the knowledge held by employees who acquire valuable organizational knowledge with them (Groff 2012; Soliman 2000). The successful implementation of new IT depends basically on the efficient HRM to ensure the successful implementation of KM, which should be directed to capture and using employees' knowledge. Moreover, intellectual assets can be more efficiently and effectively utilized if organizations apply KM techniques to leverage their HRM for achieving the organizational goals (Soliman 2000; Dalkir 2005). HRM system should enhance employees' knowledge, skills, experiences, and creativity through setting incentives and communication systems, adding to maintaining training and development programs. Accordingly, a culture of knowledge sharing should be established. Then, empowering employees and setting the appropriate work design are crucial to motivate employees for creating knowledge as well as to encourage the efficient communication and dissemination of knowledge inside the organization (Wang 2012; El Badawy 2015). Successful organizations should clearly set KM systems to promote effectively creation, storage, and sharing of knowledge to maintain their competitiveness. In turn this would require encouraging continuously employees to develop and share their knowledge as well as their experiences (Shih, 2017). The strategic knowledge of organization is rooted in the minds of its employees, not in the memory of its infrastructures. The successful implementation of KM depends mainly on the efficient HRM which should be directed to capture, use and reuse employees' valuable knowledge to reach organizations' goals. According to Soliman (2000), although information technology can be perceived as a main driver for KM, lots also disagree and believe that people is the core driver for KM not the information technology. Yet, the organization should be well equipped with appropriate technology infrastructure to support KM processes. Accordingly, HRM should manage various areas such as conflict resolution or employee appraisals to handle both the tacit and explicit knowledge. Generally to maintain competiveness and to enhance innovation, organizations should successfully operate five main KM processes that basically require HRM for supporting KM initiatives to create, to capture, to categorize, to access and to apply employees' knowledge. Implementing KM programs may be costly during the starting stage. That's why organizations should develop suitable strategies for effective implementation of KM processes. HRM functions can surely support KM strategy as follows:

- To align KM to business strategies to ensure its impact on business strategies. Then HRM should explore the employees' tacit knowledge and how to be utilized to support the achievement of business strategy.

- To identify the benefits of KM processes as sometimes can be intangible and difficult to be quantified. Then HRM should assess the degree of employees' knowledge and its expected benefits.

- To choose the proper KM program and this should be based on studying the market segment's needs. Then HRM should include strategies to encourage employees' knowledge sharing.

- To implement know how strategy reflecting the experiences and expertise of employees to become more knowledge focused. Moreover, to become a knowledge seeker through acquiring knowledge from external sources as customers or competitors. To develop a knowledge culture through clearly emphasizing the knowledge sharing as a core value to employees, adding to become a knowledge assessor to evaluate the outcomes of implementing the KM program as well as to exemplify the importance of KM through rewarding the sharing of knowledge and expertise.

- To create encouraging environments for KM program which require from HR department to promote social gatherings in order to facilitate staffs' meetings which in turn can sustain KM processes; HR department should also provide the adequate office layout of spaces for promoting staffs' informal meetings which enhance the exchange of experiences and knowledge sharing, which in turn also develop trust between employees. Moreover, through the recruitment phase, HR department should select the staff with proper cultural and linguistic backgrounds that promote the KM processes. The HR department should encourage staff to discuss openly their mistakes to create a learning organization which also promote the KM activities. 
- To enable the use of technologies for KM program. Actually the developed technologies as Internet or mobiles can promote knowledge sharing and support, as well in turn the successful implementation of KM processes. The technological infrastructure is essentially people oriented as it requires HR department support for managing the valuable knowledge of employees in the organization.

- To develop KM team to support the concept of knowledge sharing which in turn can promote the effectiveness of KM program which also basically require a suitable HR department support for enhancing teamwork spirit.

- To acquire both top management and HR department support to motivate staff for sharing knowledge, adding to generate KM leadership which requires either creating a KM role as chief knowledge officer or using a KM cross functional team or sometimes the CEO may lead the KM processes. Regardless who will lead the KM responsibility; HR department actually can support it through the effective selection process of the key person in charge (Soliman 2000; Dalkir 2005; Sunalai 2015; Shih, 2017).

Accordingly, HR department plays a major role to promote KM process through avoiding poor HR selection, poor training, low motivation, lack of succession planning or development, role confusion or conflicts, high turnover or absenteeism or unsuitable leadership. For successful KM, it is crucial to comprehend continuously and regularly three related infrastructures' levels which affect surely the KM initiatives which are the cultural, the organizational and the technical levels to discover any knowledge gap that might exist. Then HR department should make a link between knowledge strategy and actual employees' knowledge to fulfill any knowledge deficiencies through the recruitment, selection, training and development processes (Soliman 2000; Shih 2017). Core employees can provide the organization with knowledge that should be put into practice, adding to establish the appropriate organizational culture that can promote knowledge sharing. Knowledge is a valuable asset that should be very well managed to increase the organization's value and overall performance. Therefore, integrating HRM to support KM turns to be currently a crucial theme in business operations (Wang, 2012).

\subsection{Knowledge Management: Key Challenges}

"If only we knew what we know"... There is an increasing awareness of the importance of human and cultural dimensions of KM as well as the importance of content and organizing this content; so it can be easily accessed and applied as work environment is currently much more complex. There are basically major business drivers nowadays behind the increased interest of KM such as globalization creates fierce competition; there is a crucial need to maintain leaning organizations; the loss of 'Organizations Memory' because of fast workforce mobility, and Information Technological advances have expanded connectivity (Groff 2012; Dalkir 2005; Quintas 1997).

However, in order to manage successfully the knowledge practices, there are lots of challenges in terms of various essential requirements that should be adequately fulfilled as follows:

- The availability of adequate technology, IT resources, infrastructure and systems to support developing and distributing knowledge inside the organization.

- The availability of effective communication mechanisms for creating and sharing knowledge among organizational members.

- The availability of supportive mechanisms, policy and procedure for successful KM implementation inside the organization.

- The availability of reward system to reinforce and motivate employees to share knowledge and to promote $\mathrm{KM}$ processes inside the organization.

- The availability of adequate organization and management structure as supportive chain of command; adding to the initiative from top management to create $\mathrm{KM}$ culture and to manage knowledge successfully.

- The availability of effective human resource system to develop employees' understandings and competencies for successful KM implementation.

- The availability of supportive culture of openness, innovation, trust, teamwork, and entrepreneurship to promote employees' beliefs and practices to share their experiences and knowledge to perform successfully KM.

- The availability of supportive leadership reflected by top management's constant supportive actions and attitudes to embed and to enforce KM practices.

- The availability of employees' positive perception and attitudes towards KM practices and its importance to enhance the initiative and compliance to KM processes (Sunalai 2015; Nashiru 2015; Matheson 2016). 


\section{Research Methodology}

This study is an exploratory qualitative research based on a case study approach. The research questions that guide this study are as follows:

- What is Knowledge Management and why is it significant?

- What are the key drivers that support Knowledge Management initiative?

- What are the key challenges that may hinder successful Knowledge Management initiative?

- What are the recommendations for effective Knowledge Management initiative?

After reviewing the related literature review and for investigating the main research questions, an interview was illustrated with three key managers at IBM Egypt to shed the light on a good model; as a guidance supporting the crucial significance of KM for booming innovation and organizational performance.

\section{Case Study: IBM Egypt}

\subsection{IBM EGYPT: Profile Overview}

Since its establishment in 1954, IBM is actively supporting the Egyptian economy and the government's national plans through providing innovation which is essentially based on acquiring the right people and basically the knowledge management. Throughout last 60 years in Egypt, IBM supported the Egyptian Government through many initiatives in various crucial national projects that support the Egyptian economy and national plans. IBM Egypt supports the Egyptian government with the required business and technological support to develop governmental services. IBM realized that Egypt is a very attractive target as a competitive destination, that's why the outcome is being expanded to have six IBM centers in Egypt as follows:

- Cairo Technology Development Center (TDC) that provides technical excellence leadership in the region through professionals offering consultancy services relating to IBM software (SW) products.

- IBM Client Innovation Center (CIC) that provides a full range of business consulting, adding to increase the Egyptian exports of information technology.

- $\quad$ MEA Digital Sales Center in Cairo that focus on providing new markets and new solutions for emerging decision makers as developers and startups, adding to spread the digital transformation to becoming Cloud and Cognitive digital businesses.

- Global Process Services Center (GPS) Cairo that serves global commercial clients in outsourcing Finance, Human resources and Mobility Client Care support, adding to automate their daily operations.

- Global Competency Center (GCC) for Hardware that aims to establish a Remote Technical Support Center in EMEA (Europe Middle East \& Africa) capable of handling cases from within EMEA and other geographic locations like US and Canada.

- Global Competency Center (GCC) for Software that was developed for Software Remote technical support and it is serving US, Canada, Europe and MEA.

In 2017, IBM Egypt supported the Egyptian Minister for Higher Education in officially launching the first business incubator for Governmental Universities led by the Faculty of Economy and Political Sciences at Cairo University to support young Egyptian entrepreneurs to develop innovative business ideas and solutions that will solve some of the crucial problems in Egypt. IBM Egypt has also established an ecosystem and developer hub in partnership with ITIDA and the Technology Innovation and Entrepreneurship Center (TIEC). IBM Egypt focuses to working with academia for training Egyptian students and graduates and has signed an agreement with the Supreme Council of Universities in 2016 and actually reached out more than 36 universities all over Egypt and trained more than 6000 students to use technology in various fields. IBM Egypt is also hosting the Middle East and Africa Digital Sales Center that aims to transform the way IBM digitally engages with its ecosystem, across 70 countries in the region. In 2015, IBM has launched with TIEC the TIEC/IBM Cloud Computing initiative for Startups in Egypt. The initiative aims to provide resources to startups like free software, technical experts or expert mentors. IBM Egypt is always committed to develop and promote the local software innovation in Egypt. In addition, IBM Egypt practices the highest standards of corporate social responsibility as it is maintaining continuously various partnerships with governments and nonprofit organizations to innovate new means targeting capacity building, education, and social services for improving the human being conditions. IBM Egypt experts are currently working with the Ministry of Education, the Ministry of Social Solidarity and the Ministry of Youth and Sports, adding to deliver consulting expertise for various NGOs and public entities to maintain their efforts for serving Egyptian community (Adel 2018; Bakeer 2018). 


\subsection{IBM Egypt Knowledge Management: Significance, Key Drivers and Challenges}

According to Ms. Angy Mostafa, MEA Technical Vitality Program Manager - Human Resources IBM Egypt, Knowledge Management (KM) can be directly related to the improved organizational performance of IBM Egypt. KM comprises a range of strategies and practices used in IBM Egypt to identify, create, represent, distribute, and enable adoption of insights and experiences. Such insights and experiences comprise knowledge, either embodied in individuals or embedded in organizational processes or practices. KM efforts typically focus on organizational objectives such as improved performance; competitive advantage; innovation; sharing of lessons learned; integration and continuous improvement of the organization. KM efforts overlap with organizational learning, and may be distinguished from that by a greater focus on the management of knowledge as a strategic asset and a focus on encouraging the sharing of knowledge. KM efforts can help individuals and groups to share valuable organizational insights, to reduce redundant work, to avoid reinventing the wheel per se, to reduce training time for new employees, to retain intellectual capital as employee's turnover in an organization, and to adapt to changing environments and markets. KM forms an integral part of the every IBMer and IBM provides a comprehensive framework and ample opportunities on these. Learning and KM group through their learning consultants provide a framework to establish needs for learning and training for the Testing community and subsequently deliver/provide these in an effective manner. The needs of Testing Services line are in terms of Technical/Functional Capabilities, Industry Capabilities as well as Professional Development Enablement Education, which includes Core Skills, Leadership Skills, and Client-facing Skills etc. The testing professionals being closest guardians of quality of the end product or service, the knowledge of development, test methodologies and quality processes assumes paramount importance (Mostafa, 2018).

Ms. Angy Mostafa confirms as well the benefits and opportunities that IBM Egypt expect to get throughout KM implementation. The IBM community based services offering helps companies manage the information and knowledge--much of it tacit or unstructured--that often "falls through the cracks" within traditional business processes and information systems. The offering recognizes that a key factor in managing these hidden assets is a company's ability to bring communities of employees together--informal groups--with common interests and knowledge in areas relevant to the firm's success. Organizations in a range of industries, from energy producers to pharmaceutical companies, have achieved measurable returns by identifying and supporting these informal communities. These returns have taken the form of reduced operating costs, improved work productivity, and more frequent innovation. The IBM community based services offering is a part of a wide range of IBM products and services basically related to KM (Mostafa, 2018).

IBM Egypt is continuously committed to support various developers to solve the most challenging problems. Moreover, IBM Egypt is commitment to startups, developers and entrepreneurs to help them solve Egypt's most challenging problems. IBM Egypt aims to prepare the next generation to be unique and competent for developing the Egyptian society. IBM Egypt maintains technological environment to support the development and innovation in Egypt. Accordingly, KM supports IBM Egypt's innovative technologies, skills and expertise of its people to maintain its competitive advantage (Adel, 2018). IBM Egypt is continuously eager to provide unconventional and innovative ways to meet the demands of its customers across almost all industries; which cannot be realized without acquiring the right employees and maintaining an effective KM.

However, the effective KM requires key supportive drivers in terms of the availability of adequate technology, an effective communication mechanism, a supportive policy as a reward system to encourage employees for sharing their knowledge. Moreover, the effective KM requires the availability of an adequate organic adaptable organizational structure, effective human resource department to acquire the right employees and to develop their competencies, adding to a supportive organizational culture for enhancing innovation, teamwork and trust. All of which require certainly the top management's supportive actions to enforce KM initiative at IBM Egypt. Regarding the obstacles that IBM Egypt may face throughout KM implementation or that may prevent KM success; one of the main challenges of KM is that of getting people to share their knowledge as Ms. Angy Mostafa clarified. Why should people give up their hard-won knowledge, when it is one of their key sources of personal advantage? In some organizations, sharing is natural. In others the old dictum "knowledge is power" reigns.

\section{Conclusion and Recommendations}

The significance of KM for developing the organizational innovative performance and for maintaining the organizational competitiveness has been demonstrated through the case study of IBM Egypt. Recently, KM initiative for acquiring and creating knowledge has become an essential base to cope with the dynamic unpredictable challenging global environment. KM can stimulate the innovation that in turn sustain competitive 
advantage and improve the overall organizational performance.

The study highlights the significance of KM and explores the key drivers that support organizational KM as well as it draws the attention to the challenges that may hinder its successful implementation. Accordingly, it is recommended to ascertain key supportive drivers for advancing successfully the flow of KM throughout the organizations in Egypt. The successful application of KM initiative requires two interconnected crucial factors in terms of both organizational management and human orientation.

First is the organizational management that should support KM through setting the appropriate organizational structure in terms of providing the required technological infrastructure, the supportive chain of command, policies, procedures, adding to set an effective human resources management to foster communication for knowledge creation and sharing. Secondly is the human orientation that comprises the supportive organizational culture, leadership and top management support, to promote positive attitudes and initiatives toward KM. In turn, KM initiative should be supported by organizational culture to foster innovation, to be people and teamwork oriented, adding to enhancing a climate of trust for sharing knowledge. In fact, the organizational culture is a vital aspect affecting KM initiative as it influences employees' perceptions of organizational commitment to KM. Moreover, effective HRM is crucial for acquiring the right employees and for setting a motivation system for employees to support a successful implementation of KM initiative.

At the end, as for future research, this study sheds the light for expanding further qualitative and quantitative research potentials to evaluate KM dynamics and outcomes for developing organizational performance.

\section{References}

Adel, R. (2018). Communications and Media Relations Manager IBM Egypt, Interview.

Bakeer, N. (2018). CWA, EA and NWA Operations Leader-Software Services IBM Watson Customer Engagement, Interview.

Bohle, D. (2016). From Knowledge Intensive to Wisdom Based Services. Integral European Conference, 2016.

Braedley, S. (2016). Research on Fire: Lessons Learned in Knowledge Mobilization. Technology Innovation Management Review, 6(9), 53-58.

Caiazza, R., Aileen, R. \& David, A. (2015). Knowledge Effects on Competitiveness: From Firms to Regional Advantage. Journal of Technology, 899- 909.

Dalkir, Kimiz (2005). Knowledge Management in Theory and Practice, Elsevier Inc.

El Badawy, T. A. \& Mariam, M. M. (2015). The Practice of Knowledge Management in Private Higher Education Institutions in Egypt: The Demographics Effect. International Journal of Business Administration, 6(2), 96-105.

Gascó,V. P., Ismael, Q. P. \& Carlos, P. C. (2017). Knowledge Management and Organizational Culture in a Software Development Enterprise. Journal of Small Business Strategy, 27(1), 37-49.

Groff,T. \& Thomas, J. (2012). Introduction to Knowledge Management. Business \& Economics. Routledge.

Kianto, A., Mika, V. \& Pia, H. (2016).The Impact of Knowledge Management on Job Satisfaction. Journal of Knowledge Management, 20(4), 621-636.

King,W. R. (2009). Knowledge Management and Organizational Learning (Annals of Information Systems). Business \& Economics, 15-39.

Kraśnicka,T.,Wojciech, G. \& Martyna, W. P. (2016). Management Innovation and its Measurement, Journal of Entrepreneurship, Management and Innovation (JEMI), 12(2), 95-122.

Makhmutov, I.I., Isavnin, A.G. \& Karamyshev, S.A. S. (2016). Classification Approach in Determination of Knowledge in Context of Organization. Academy of Strategic Management Journal, 15, 39-45.

Matheson, K. \& Cathy, M. E. (2016). Perspectives on Knowledge Mobilization: An Introduction to the Special Issue. Technology Innovation Management Review, 6(9), 4-8.

Mir, R., Rajiv, K., Ali, M. \& Martin, G. (2015). Managing Knowledge in the Age of Global Capital. Academy of Strategic Management Journal, 14(2), 129-140.

Mostafa, A. (2018). MEA Technical Vitality Program Manager-Human Resources IBM Egypt, Interview.

Nashiru, Z. M. \& Singh, R. K. (2015). Exploring Knowledge Creation, Implementation and Practice by Banking Leaders at the Central Bank Of Ghana. Leadership \& Organizational Management Journal, 3, 42-53. 
Overall, J. (2015). A Conceptual Framework of Innovation and Performance: The Importance of Leadership,Relationship Quality, and Knowledge Management. Academy of Entrepreneurship Journal, 21(2), 41-54.

Quintas, P., Paul, L. \& Geoff, J. (1997). Knowledge Management: A Strategic Agenda. Long Range Planning, 30(3), 385-391.

Shih, Y. Y., Lu,Y. H., Liu, T. Y. \& Wu, M. F. (2017). The Staffs' Adoption Intention of Knowledge Management System in Green Hospital-The Theory of Technology Acceptance ModelApplied. The International Journal of Organizational Innovation, 9(3), 27-35.

Soliman, F. \& Keri, S. (2000). Strategies for Implementing Knowledge Management: Role of Human Resources Management. Journal of Knowledge Management, 4(4), 337-345.

Sunalai, S. \& Michael, B. (2015). Exploring Knowledge Management in Higher Education Institutions: Process, Influences, and Outcomes. Academy of Educational Leadership Journal, 19(3), 289-308.

Tomas, G. \& Hult, M. (2003). An Integration of Thoughts on Knowledge Management. Decision Sciences, 34, 189-195.

Wahba, M. (2015).The Impact of Organizational Structure on Knowledge Management Processes in Egyptian Context. The Journal of Developing Areas, 49(3), 275-292.

Wang, K. L., Chi, C. \& Tung, C. M. (2012). Integrating Human Resource Management and Knowledge Management: From the Viewpoint of Core Employees and Organizational Performance. The International Journal of Organizational Innovation, 5(1), 109-137.

Wiig, K. M. (1997). Knowledge management: Where did it come from and where will it go?Expert Systems with Applications, 13(1), 1-14.

Wiig, K. M. (1997). Supporting Knowledge Management: A selection of Methods and Techniques. Expert Systems with Applications, 13(1), 15-27.

Wu, W. L., Lee, Y. C. \& Shu, H. S. (2013). Knowledge Management in Educational Organizations: A Perspective of Knowledge Spiral. The International Journal of Organizational Innovation, 5(4), 7-13.

Zahra, S. A. (2015). Corporate Entrepreneurship as Knowledge Creation and Conversion: The Role of Entrepreneurial Hubs. Small Business Economics, 44, 727-735.

\section{Copyrights}

Copyright for this article is retained by the author(s), with first publication rights granted to the journal.

This is an open-access article distributed under the terms and conditions of the Creative Commons Attribution license (http://creativecommons.org/licenses/by/4.0/). 